\title{
El patrón de industrialización de México subordinado a la maquiladora estadounidense
}

En este trabajo se aborda la manera en que el nuevo patrón o estilo de desarrollo industrial que ha seguido México desde mediados de los años ochenta tiende a definirse en torno al estándar y a las exigencias de un modelo maquilador como puntal de un desarrollo

La maquila es considerada como la forma idónea en la que opera la racionalidad económica de las empresas transnacionales. A través de los datos analizados, en este artículo se constata cómo el proceso maquilador ya no se limita a la franja fronteriza, sino que cubre gran parte del territorio mexicano. Con los esquemas de globalización y flexibilización imperantes en la economía mundial, así como las políticas de apertura y de liberalización no discriminatorias implementadas por México, todo parece apuntar a que se fortalecerá el patrón de acumulación o "estilo de desarrollo", apoyado en un proceso ensamblador, en el cual las inversiones de los capitales transnacionales sean las encargadas de acelerar la especialización sectorial (productos exportables) esparcidos en la geografía nacional.

Palabras clave: maquila, industria, política industrial, transnacionales, producción mundial.

- Investigador de la Universidad de Colima, México.

merchand@ucol.mx industrial de carácter internacional, pero restringido al ámbito de los intereses intrafirma de las transnacionales estadounidenses.

Encontramos los antecedentes de este nuevo estilo a mediados de los años sesenta, cuando en la frontera entre Estados Unidos y México se fomenta el modelo de maquila industrial. Modelo que en la actualidad ya no se limita sólo a los estados fronterizos, sino que se extiende por todo el territorio nacional.

A fin de explicar con cierta amplitud el significado que en conjunto adquiere la operacionalización de las transnacionales a través de la industria maquiladora de exportación, hemos divido este capítulo en tres grandes apartados: 
1. La economía mexicana transita de las ventajas comparativas clásicas a las ventajas comparativas dinámicas o competitivas.

2. El paso de oferente de productos primarios a manufactureros.

3. La industria maquiladora consolida su crecimiento en el territorio nacional.

\section{La economía mexicana transita de las ventajas comparativas clásicas a las ventajas comparativas dinámicas o competitivas.}

En este punto quedará demostrado cómo en la escisión del proceso productivo que da lugar a la maquila - y para que ésta funcione de manera óptima- es necesario contar con nuevas condiciones en el entorno económico del país receptor, es decir: que se operen cambios en la política industrial del Estado, los cuales consisten no sólo en ofrecer mano de obra barata y abundante, sino en que se implemente un paquete de estrategias de política industrial que arraigue y atraiga nuevas inversiones de subsidiarias extranjeras.

La descripción de esta nueva política industrial define pautas que sustentan el espacio territorial a partir de la construcción no únicamente de la ventajas comparativas clásicas, sino combinadas con la creación ex profeso de ventajas competitivas basadas no sólo en una reducción constante del salario real, sino a partir de políticas que subsidien (estímulos e incentivos de promoción industrial) a las filiales de los corporativos transnacionales.

El siguiente esquema ejemplifica cómo se ha ido integrando una nueva configuración regional, a partir de otros determinantes que transitan entre las ventajas comparativas clásicas y las competitivas: ${ }^{1}$

I. La diferencia entre ventajas comparativas y competitivas se analiza en forma 
Esquema 1

Nueva configuración regional en la región metropolitana de Guadalajara (RMG)*

\begin{tabular}{|l|}
\hline Ventajas \\
comparativas \\
Abaratamiento \\
del costo de la \\
mano de obra, \\
mediante con- \\
tratos salariales \\
rígidos y grados \\
de flexibilidad en \\
las contratacio- \\
nes a favor del \\
capital empresa- \\
rial.
\end{tabular}

rial.
Región que se define a partir de la combinación entre ventajas comparativas y competitivas. Las TRN propician, junto con los actores locales, un nuevo patrón industrial

\section{industrial}

Se crea una sinergia interna para cumplir con los parámetros fijados por la empresa estadounidense globalizada. Se forman áreas productivas especializadas, orientadas exclusivamente a la exportación.

\section{Ventajas}

competitivas

Política industrial que promueve un comercio exterior sustentado por las filiales extranjeras. A fin de que el territorio y sus unidades económicas (regiones) sean competitivos, el Estado debe crear una atmósfera industrial a favor de estos capitales. Para atraer el capital transnacional se deben crear las condiciones competitivas a través de una política de fomento y de desregulación a favor de la IED, y apoyada por el instrumento de una política de apertura comercial e industrial a través de incentivos e estímulos.

* Para allegarse capitales externos, las entidades federativas deben basarse en ofrecer calidad del marketing (promocionar su ventajas locativas en los mercados externos). En tanto que el capital transnacional considerará el "entorno territorial" como la condiciones favorables que le permitan seleccionar las regiones donde se ofrezcan las mejores garantías para decidir ubicarse.

muy esquemática. No existen las condiciones para entrar a debatir las controversias teóricas sobre dichos conceptos. Simplemente se utiliza el concepto de ventaja comparativa para ilustrar el clásico ejemplo de que los países ya no pueden competir en el mercado internacional valiéndose únicamente de sus recursos naturales o de los salarios bajos para atraer capital extranjero, sino que para competir son necesarios otros recursos, creados deliberadamente para que los capitales decidan localizarse en el país receptor. 
Para explicar la "combinación o transición" entre el significado de las ventajas comparativas y el de las competitivas en México, se tratará de enmarcar la definición de estilo o patrón de acumulación dentro del concepto que operacionaliza el quehacer de la política industrial seguida por el Estado-nación o Estado-local, consistente en reorientar la ofensiva exportadora a través de un cambio en su giro productivo, enfocado a la exportación de productos manufactureros sustentados mediante el esquema de plantas maquiladoras - principalmente de capital estadounidense-, en claro detrimento del papel que tenía el país como exportador de algunos productos primarios.

De acuerdo a Krugman y Obstfeld (1999), el comercio creciente entre países de salarios bajos y países de salarios altos produce en ocasiones un comercio que se clasifica como intraindustrial, aunque en realidad es un comercio generado por la ventaja comparativa.

Supongamos, dice Krugman, que en California, EU, una empresa estadounidense produce unos sofisticados chips para computadoras, los embarca hacia Asia, donde son ensamblados, y de ahí los reembarca una vez más hacia casa. Tanto los componentes exportados como la computadora importada van a ser seguramente clasificados como "computadoras y productos asociados", de tal modo que las transacciones van a contar como comercio intraindustrial.

Sin embargo, lo que está ocurriendo en realidad es que los Estados Unidos exportan productos intensivos en tecnología (chips) e importan un servicio intensivo en trabajo (ensamblado de computadoras). Este comercio "pseudointraindustrial" es muy común entre los EU y México. Independientemente de la postura que se adopte, las ventajas que puede tener una nación con respecto a otra en la actualidad son aquellas que deliberadamente se desarrollan para dar fortaleza a un país. 
Se ha pasado así de un enfoque que privilegiaba el uso de las ventajas básicas —es decir, los factores con los que de manera natural y no planeada ha sido dotada una región- a otro en que son más bien determinantes las ventajas comparativas "dinámicas" o competitivas, es decir aquellas que no se consiguen de manera pasiva y de forma natural, sino que se adquieren y buscan deliberadamente y que se refieren aspectos como la infraestructura avanzada o el personal con altos niveles de calificación. Factores que deben perfeccionarse y mejorarse a lo largo del tiempo a través de un esfuerzo deliberado.

Para Porter (1996) este concepto de ventaja competitiva, aunque la mayor parte de las veces se refiera a empresas, no por ello deja de aplicarse a regiones o Estados; si se parte del supuesto que tanto las entidades federativas como las empresas cuentan con recursos naturales natos y con los aprendidos de la experiencia, en el caso del Estado esto podría ser la construción de una carretera o un aeropuerto.

Así pues, la ventaja competitiva es aquel escenario constituido por un diamante integrado por cuatro vertientes

- Condicionantes de los factores. Hace referencia a la posición de la región en lo que concierne a mano de obra especializada o infraestructura necesaria para competir en un sector dado.

- Condiciones de demanda. La naturaleza de la demanda interior de los productos y/o servicios del sector.

- Sectores afines y de apoyo. La presencia o ausencia de sectores proveedores y sectores afines que sean internacionalmente competitivos.

- Estrategia, estructura y rivalidad de la empresa. Las condiciones vigentes de la nación con respecto a cómo se crean y gestionan las compañías, así como la naturaleza de la rivalidad doméstica. 
A partir de estos cuatro factores, Porter señala que el diamante es un sistema mutuamente auto-reforzante, ya que el efecto de un determinante depende de los otros, y viceversa. Existen dos variables adicionales que influyen en el diamante de Porter: la causalidad y el gobierno.

Los acontecimientos causales están fuera del control tanto de las empresas como del gobierno. Tal es el caso de la migración de una maquiladora a otro país, debido a las fluctuaciones de los precios internacionales de sus productos, derivados de las innovaciones tecnológicas en los procesos productivos.

Respecto al gobierno, su función tiene que ver con la ayuda otorgada a la empresa para incitarla a localizarse o que reinvierta en la región receptora. Estas políticas pueden tomar varias formas:

Subvenciones directas a la empresa en forma de subsidios determinados, por ejemplo, en función del número de empleos creados en la región.

Subvenciones directas a la empresa según objetivos precisos: capacitación, inversión, adquisiciones de equipo, etcétera.

Desgravaciones fiscales: deducciones de impuestos sobre las ganancias, reducción de impuestos (IVA, impuestos prediales, etc.), subvenciones indirectas de todo tipo que reduzcan la carga fiscal de la empresa.

Medidas de reducción de costo del capital: condiciones preferenciales de crédito (garantías de préstamos, tasas de interés privilegiadas, etcétera).

Rebajas sobre ciertos costos, tarifas de electricidad, tarifas postales, infraestructuras, etcétera (Polese, 1998: 265).

Las formas de ayuda financiera directa e indirecta a la empresa son casi ilimitadas, y varían según las circunstancias y las necesidades. Pero se trata siempre de subvenciones en el sentido económico del término, en la medida 
en que las empresas de las regiones designadas reciben un tratamiento privilegiado, que supone una transferencia de dinero a su favor, asumido por los contribuyentes de otras regiones. Sin embargo, a menudo es difícil calcular el verdadero valor de esta transferencia, en la medida en que la subvención sea más directa o, por el contrario, más indirecta u oculta.

El grado de intervención del gobierno y sus políticas juegan un papel determinante en la competitividad de un país; y en el caso concreto de México, el gobierno refuerza los atributos propios de las empresas transnacionales estadounidenses.

\section{El paso de oferente de productos primarios} a oferente de productos manufactureros

La estrategia económica neoliberal impuesta a partir de 1982 "abandonó la inversión estatal en algunos rubros considerados no prioritarios", orientó la producción hacia el mercado exterior, concentró el capital nacional y propició la penetración del capital extranjero, permitiendo el crecimiento de las exportaciones manufactureras en medio de un mercado deprimido. El aparato productivo experimentó una profunda transformación que aumentó la heterogeneidad industrial; el llamado re-despliegue industrial se aceleró por medio del esquema de subcontratación (maquiladoras), mientras se producía el desplome de la inversión productiva en las industrias básicas tradicionales (Morales, 1992: 109).

En la década de los ochenta, con el cambio de régimen económico fundamentado en un "desarrollo hacia afuera" (estilo de desarrollo), en lugar de "desarrollo hacia adentro" y la redefinición de un nuevo paradigma industrial fundamentado en una reestructuración industrial flexible, los llamados países periféricos se perfilan tendencialmente 
a desarrollar una industria de ensamble o terminado de productos. Su principal objetivo se encaminó al logro de menores costos durante el proceso productivo global, con el fin de abaratar precios en el mercado y obtener mayores utilidades. Objetivo que ha podido articularse debido al ahorro en costos de mano de obra (diferencia de salarios entre países) y a la nueva forma de intervención del Estado para apoyar la inversión extranjera.

La proximidad al mercado estadounidense, la liberación unilateral del comercio por parte de México, las perspectivas de una mayor integración a través del Tratado de Libre de Comercio de América del Norte (TLCAN), entre otros factores, han atraído un flujo creciente de inversión extranjera cuyo propósito principal ha sido incrementar las ventas a Estados Unidos. De esta manera, las exportaciones de las empresas estadounidenses se han convertido en un objetivo por sí mismas, más que limitarse al cumplimiento de un requisito formal establecido por el gobierno mexicano.

Como se verá más adelante, el comportamiento del comercio intraindustrial e intrafirma en materia de productos electrónicos (computadoras y otros) está estrechamente vinculado. Primero, porque un reducido número de transnacionales controla la mayor parte del comercio exterior (en gran medida intrafirma); y segundo, porque conforme a su estrategia, éstas concentraron sus inversiones en incrementar las exportaciones de determinados productos, creando una red de empresas para distribuir las importaciones de otros productos de la matriz.

En el cuadro 1 se muestra la participación de las manufacturas de México con su principal mercado de destino, el estadounidense. 


\section{Cuadro 1}

Estructura de las exportaciones de México a los Estados

Unidos de América (porcentajes)

\begin{tabular}{lrrrr} 
& 1980 & 1985 & 1990 & 1996 \\
1. Recursos naturales & 63.0 & 49.1 & 27.8 & 17.2 \\
1.1 Agricultura & 13.3 & 10.9 & 10.4 & 7.0 \\
1.2 Energía (principalmente petróleo) & 47.6 & 36.0 & 15.7 & 9.1 \\
1.3 Fibras textiles, minerales y & 2.2 & 2.3 & 1.6 & 1.1 \\
menas de metal & & & & \\
2. Manufacturas & 34.1 & 48.0 & 67.8 & 79.0 \\
2.1 Basadas en recursos naturales & 4.2 & 3.6 & 3.1 & 2.1 \\
2.2 No basadas en recursos naturales & 29.9 & 44.5 & 64.7 & 76.9 \\
Otros & 2.8 & $2 . .9$ & 4.5 & 3.9 \\
\hline
\end{tabular}

Fuente: Mortimore et al. (2000: 46).

Como se puede observar, la estructura de las exportaciones registra un movimiento a favor de las manufacturas respecto al de los recursos naturales. Las manufacturas crecieron: de $34.1 \%$ en 1980 , a $79 \%$ en 1996 ; mientras que los recursos naturales cayeron: de $63 \%$ en 1980 , a $17.2 \%$ en 1996.

De esta manera, si consideramos los cambios normativos a favor de la inversión extranjera directa (IED), así como los factores de producción relativamente baratos comparables con los países asiáticos, la frontera norte de México y otras entidades al interior se están configurando en un espacio estratégico para el ensamble y subensamble de la industria de computación estadounidense.

De acuerdo con la CEPAL (cuadro 2), México se ha convertido en el tercer proveedor más importante del mercado estadounidense. 


\section{Cuadro 2}

Importaciones de Estados Unidos de América en industrias seleccionadas (en millones de dólares y porcentajes)

\begin{tabular}{lrr} 
& \multicolumn{1}{c}{1998} & $1998 \%$ \\
Totales & 907,647 & 100.0 \\
Canadá & 174,685 & 19.3 \\
Japón & 121,313 & 13.4 \\
México & 93,017 & 10.3 \\
China & 70,815 & 7.8 \\
Alemania & 49,769 & 5.5 \\
& & \\
1. Industria electrónica & 124,581 & 100.0 \\
México & 24,400 & 19.6 \\
Japón & 22,870 & 18.4 \\
China & 12,573 & 10.1 \\
Canadá & 9,763 & 7.8 \\
Malasia & 8,346 & 6.7 \\
& & \\
2. Industria automotriz & 126,313 & 100.0 \\
Canadá & 46,323 & 36.7 \\
Japón & 34,767 & 27.5 \\
México & 16,732 & 13.3 \\
Alemania & 13,810 & 10.9 \\
Reino Unido & 2,967 & 2.4 \\
& & \\
3. Industria de la confección & 49,719 & 100.0 \\
México & 6,701 & 13.5 \\
China & 5,661 & 11.4 \\
Hong Kong & 4,437 & 8.9 \\
República Dominicana & 2,311 & 4.7 \\
Taiwán & 2,000 & 4.0 \\
\hline & & \\
& & \\
& & \\
& & \\
& &
\end{tabular}

Fuente: Elaboración a partir de CEPAL, 1999.

Durante los años noventa, México alcanzó un poco más de $10 \%$ de las importaciones totales de las que realizó Estados Unidos en el año de 1998. Fenómeno importante, especialmente en la industria electrónica, que muestra que 
el país proveyó al vecino del norte, en 1998, con $20 \%$ de las importaciones.

Cabe destacar que, en este mismo año, la industria automotriz sobrepasó a Alemania; y la de confecciones, a China. De ahí el destacado papel de México en las importaciones de Estados Unidos, sobre todo en industrias donde la búsqueda de eficiencia se convierte en factor básico de la competitividad internacional.

\section{La industria maquiladora consolida su crecimiento} en territorio nacional

Si bien la industria maquiladora transita por una economía más competitiva, ésta, como bien lo señaló Fajnzylber (1998), es una competitividad "espuria", pues todavía se basa en operaciones de ensamblado de baja remuneración, incentivadas por el mercado estadounidense.

Como se ha mostrado anteriormente, la ofensiva exportadora de la política industrial se ha orientado al mercado de los Estados Unidos. Y ha sido exitosa gracias a los privilegios arancelarios concedidos para la importación, además de contar con operaciones de ensamblado de baja remuneración.

De acuerdo al informe de 1998 sobre inversión extranjera elaborado por la Comisión Económica para América Latina y el Caribe (CEPAL, 1998), 60\% de la inversión que llega al país proviene de Estados Unidos. Estos capitales ingresan a México para desarrollar sistemas continentales de producción integrada, que mejoran la eficiencia y la competitividad en la exportación de manufacturas al país vecino.

El cuadro 3 indica la posición de México en Latinoamérica respecto a los principales focos de atracción de los flujos de la inversión extranjera directa. El mismo documento de la CEPAL señala que entre los factores esenciales que atraen dicha inversión se encuentran el acceso a mercados tanto 
hacia los Estados Unidos como hacia América Latina, debido a los tratados y acuerdos firmados, costo competitivo de insumos y el clima de negocios atractivo.

Cuadro 3

Posición de México en Latinoamérica

\begin{tabular}{|c|c|c|c|c|c|c|c|c|c|}
\hline \multicolumn{10}{|c|}{ Primario Manufactura Servicios } \\
\hline & $\begin{array}{c}\text { Petró- } \\
\text { leo }\end{array}$ & $\begin{array}{c}\text { Mine- } \\
\text { ría }\end{array}$ & $\begin{array}{c}\text { Ali- } \\
\text { mentos }\end{array}$ & Autos & $\begin{array}{l}\text { Electró- } \\
\text { nicos }\end{array}$ & $\begin{array}{l}\text { Ma- } \\
\text { quila }\end{array}$ & $\begin{array}{l}\text { Tele- } \\
\text { com. }\end{array}$ & $\begin{array}{c}\text { Ener- } \\
\text { gía }\end{array}$ & Banca \\
\hline Argentina & $\mathrm{X}$ & $\mathrm{X}$ & $\mathrm{X}$ & $\mathrm{x}$ & & & $\mathrm{X}$ & $\mathrm{X}$ & $\mathrm{x}$ \\
\hline Brasil & & & $\mathrm{X}$ & $\mathrm{X}$ & & & $\mathrm{X}$ & $\mathrm{x}$ & $\mathrm{X}$ \\
\hline México & & & $\mathrm{X}$ & $\mathrm{x}$ & $\mathrm{x}$ & $\mathrm{X}$ & & & $\mathrm{X}$ \\
\hline Chile & & $\mathrm{x}$ & & & & & $\mathrm{x}$ & $\mathrm{X}$ & $\mathrm{X}$ \\
\hline Colombia & $\mathrm{x}$ & & & & & & & $\mathrm{X}$ & $\mathrm{x}$ \\
\hline Perú & & $\mathrm{x}$ & & & & & $\mathrm{X}$ & $\mathrm{X}$ & \\
\hline Venezuela & $\mathrm{x}$ & & & & & & $\mathrm{X}$ & & $\mathrm{x}$ \\
\hline A. Central & & & & & & $\mathrm{X}$ & & $\mathrm{X}$ & \\
\hline Caribe & $\mathrm{X}$ & & & & & $\mathrm{X}$ & & & $\mathrm{X}$ \\
\hline
\end{tabular}

Fuente: CEPAL (1998).

El proceso maquilador se ha expandido porque ha contado con un marco legal propicio para ampliar el comercio exterior y también porque se le han otorgado facilidades de tipo fiscal, monetario y laboral. A treinta años de realizar operaciones en México, el sector maquilador se ha constituido como uno de los renglones generadores de empleo y divisas, en un mecanismo impulsor de la comercialización de productos en el exterior, procedentes éstos en su gran mayoría de empresas estadounidenses.

La importancia de esta industria se aprecia mediante la presentación de los siguientes datos respecto a la dinámica que ha tenido en su conjunto.

El número de maquilas, en términos de crecimiento absoluto de nuevos establecimientos, fue de 629 empresas y de 173,128 empleos en 1983; para 1998 hubo en operación 
2,936 empresas con una ocupación para 950,575 trabajadores, cifra que representa $18.6 \%$ del empleo total del sector manufacturero en ese año (CNIME, 2000).

En términos absolutos, Chihuahua se mantuvo como el estado donde las maquiladoras emplean a mayor número de trabajadores, con un total de 261,103 al cierre de 1998. Le sigue Baja California, con 214,101 empleados; y en tercer lugar está Tamaulipas, con 157,950. Del total de empleados de la industria maquiladora de exportación en 1998, el 57\% son mujeres y $43 \%$ hombres (INEGI, 2000).

En cuanto a la diversificación geográfica, el mayor número de empresas maquiladoras se ubican, en 1998, en $81.2 \%$ en las ciudades fronterizas, y $18.8 \%$ en el resto del país (Seijal, 1999).

Por lo que toca a los datos más agregados y al comportamiento de maquila en la economía en los rubros de la exportación, esta industria se constituye en una importante fuente generadora de divisas para el país, con una captación neta que sobrepasa los 10 mil mdd en 1998 - cuadro 4- (Banco de México, 1999).

La industria maquiladora ha desarrollado una carrera ascendente, toda vez que las exportaciones de las más de tres mil plantas instaladas en el territorio nacional se duplicaron de 1994 a 1998, cuando pasaron de 26 mil 269 millones de dólares a 53 mil 083 millones.

Sólo en 1998, sin las ventas de las maquiladoras, las estadísticas del comercio exterior, en lugar de reflejar 117 mil 501 millones de dólares en exportaciones, apenas sumarían 64 mil 637 millones. En los últimos cuatro años, la participación de este sector en las ventas totales del país creció de $43 \%$ a $45 \%$.

La participación de la industria maquiladora se hace más importante, pues en 1994 — de acuerdo a las cifras de comercio exterior de México- el déficit comercial de la economía mexicana (sin incluir a las maquiladoras) 
ascendió a 18 mil 700 millones de dólares. Este déficit se reduce a -5,360 mdd al incluir en las cuentas el superávit de la industria de exportación, que ascendió a 13 mil 340 millones de dólares (cuadro 4).

Como se aprecia en el cuadro, del total exportado (136,707 mdd) las mercancías de origen petrolero representaron en 1999 el $7.3 \%$ y las no petroleras el restante $92.7 \%$. Dentro de estas últimas, las ventas agropecuarias representaron $3.0 \%$ del total, las extractivas (sin petróleo) $0.3 \%$ y las manufacturas $89.4 \%$.

En la composición de estos porcentajes, casi la mitad (46.6\% del total) corresponde a las maquiladoras (98\% de los componentes se importa). Ciertamente, las maquiladoras exportaron 63 mil 749 millones de dólares, pero para ello importaron 50 mil 409 millones de bienes intermedios (partes componentes, materias primas y otros insumos).

Si observamos con detenimiento el anterior cuadro, vemos que el saldo neto de maquiladoras es positivo, es decir, se reporta un flujo neto que permite cuantificar con más realismo el valor de las exportaciones totales que realizan las maquilas. Así, se puede deducir que de 1994 a 1999 las exportaciones "netas" ${ }^{2}$ que realizan las maquilas aumentaron año con año: de 5, 803 a 13,340 mil millones de dólares.

Respecto a las importaciones, del total de importaciones de mercancías (142,063 mdd) en 1999, 8.6\% correspondió a bienes de consumo, $77.0 \%$ a bienes intermedios y el restante $14.4 \%$ a bienes de capital (maquinaria y equipo para producción). Del $77.0 \%$ de bienes intermedios, las maquiladoras importan entre $35.5 \%$ y $41.5 \%$, que corresponden al resto de la industria.

\footnotetext{
2. El criterio de flujos netos facilita medir con más realismo esa contribución. Ello es así en virtud de que se cuantifican en función de su valor agregado nacional (VAN), y no a su valor bruto.
} 


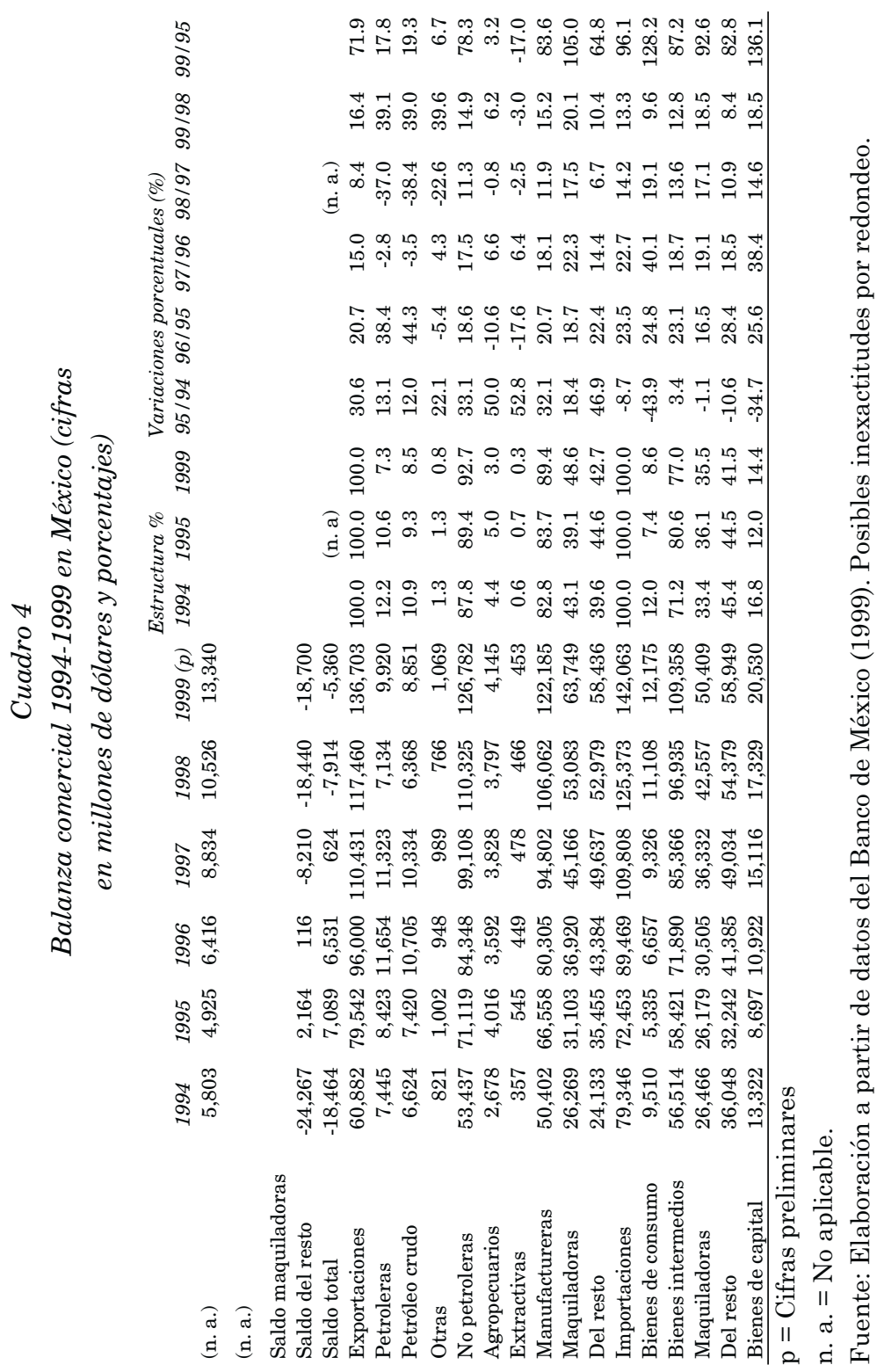

Sociedad E No. 31 
Habría que hacer todavía algunas precisiones respecto a las importaciones. En rigor, los insumos importados por la industria maquiladora no significan una erogación real de divisas, pues se trata de operaciones entre compañías vinculadas (matriz y filial o subsidiaria) que no entrañan movimientos en efectivo, pues existen diferentes formas de operación de la industria maquiladorsa que no necesariamente corresponden a una relación matriz-subsidiaria, generalmente se trata de operaciones entre intereses vinculados, maquiladora y cliente.

Entre los sectores de exportación más importantes del país, por ejemplo el de la industria automotriz y el de equipo electrónico, algunos se conforman de subsidiarias de corporaciones del exterior (GM, Ford, IBM, etc.), las cuales reciben de sus matrices los componentes que incorporan a los bienes de exportación. Estas operaciones se llevan a cabo en cuentas "entre compañías", sin involucrar pagos de efectivo.

Debido al cambio estructural realizado principalmente en su sector exportador industrial, en los últimos 12 años la economía mexicana ha acentuado su dependencia respecto a la economía estadounidense. En este sentido, México se considera una economía abierta bajo estándares internacionales, ya que su comercio exterior representa $57 \%$ del PIB, esto es, más de 20 puntos porcentuales del nivel que se tenía hace seis años. Cifra mayor que el promedio de los países latinoamericanos, en los casos de Argentina y Brasil, es de $22 \%$ y $15 \%$ respectivamente (Sandoval, 2000).

Hace veinte años el gobierno federal puso en marcha programas de fomento a las exportaciones, cuyo esquema de operación consistió en permitir la importación de materias primas libres de pago de aranceles, con el fin de utilizarlas como insumos en la manufactura de mercancías destinadas exclusivamente para su reexportación. 
Los dos mecanismos conocidos para tal fin son el Programa de Importación Temporal para Productos de Exportación (Pitex) y el de Fomento y Operación de la Industria Maquiladora de Exportación (maquila). Sin embargo, de acuerdo al TLCAN y conforme a los compromisos internacionales adquiridos por el país, para el 1 de enero de 2001 los programas de importación temporal tenían que ser "suspendidos o modificados".

Compromisos internacionales que no han sido atendidos por la actual Secretaría de Economía del gobierno foxista, la cual ha decidido conceder una tregua a la industria del ensamble para que ésta no pague aranceles por los insumos que adquiera y así permitir que las maquilas operen como lo hacían antes de 2001, es decir: bajo la regla octava. ${ }^{3}$ Dicho instrumento establece un mecanismo que permite realizar, mediante una sola fracción arancelaria, la importación de un número amplio de insumos empleados en la producción de mercancía específica destinada a la exportación. Este esquema se orienta a facilitar la importación de insumos cuando, por ejemplo, éstos provienen de múltiples regiones o entren al país en distintas fechas de embarques. A fin de continuar ampliando la regla octava bajo los programas de promoción sectorial (Prosec), simplemente se modificaron las fracciones arancelarias para armonizar los intereses comerciales entre México y Estados Unidos.

La cuestión radica en saber si esta ofensiva exportadora se constituye efectivamente en un buen motor de desarrollo:

Existen distintas maneras de expandir las exportaciones de un país [...] Algunas pueden ser más conducentes al desarrollo que otras. La competitividad internacional puede lograrse a través de la reducción constante del salario real, a expensas del medio ambiente o mediante subsidios que el gobierno otorga a las empresas a costa de aumentar

3. Declaraciones de la subsecretaria de Comercio Interior de la Secretaría de Economía, Rocío Ruiz Sandoval (citado en Saldaña y González, 2000).

Sociedad B No. 31 
los déficit fiscales. Puede que las exportaciones basadas en uno de esos factores no conduzcan al desarrollo sustentable. El extinto Fajnzylber, que había coordinado el estudio de la CEPAL, denominó a estas formas "competitividad espuria" (Buitellar y Padilla, 1999: 134).

Todo parece demostrar que la descripción de "competitividad espuria" encaja muy bien con el estilo o patrón de acumulación (ofensiva exportadora) que se ha seguido desde hace más de veinte años, y que ha acentuando las redes de producción y comercio de grandes firmas multinacionales extendidas por todo el espacio nacional; asimismo, la posición creciente del país en los flujos comerciales mundiales no puede ser explicada sin la presencia de las transnacionales y de la subcontratación internacional, cuya expresión más nítida es la maquila de exportación.

Los datos del INEGI (2000) confirman que el comercio exterior se ha convertido en el motor del crecimiento, pero apoyado fuertemente por la industria maquiladora ( $E l$ Financiero, 2000: 9A):

- En el primer semestre de 2000, la industria manufacturera contribuyó con $86.9 \%$ de las exportaciones totales; en tanto que la pequeña y mediana industria, con sólo $2 \%$.

- La pequeña y mediana industria representan $90 \%$ de los establecimientos, y apenas contribuyen con alrededor de $25 \%$ del PIB nacional.

- El promedio de contenido nacional en cada producto que se comercializa en el exterior es de $30 \%$, y el restante $70 \%$ está constituido por insumos importados.

Si bien es cierto que la economía mexicana ha crecido en su dinámica exportadora, ésta ha sido superada por el crecimiento de las importaciones.

Después de la firma del TLCAN, los cambios experimentados por la economía mexicana en cuanto a los esquemas de producción compartida, a través del análisis de los flujos 
de comercio registrados bajo los programas de maquila de exportación, la llevaron a registrar una tasa de crecimiento promedio anual de $10.7 \%$. En 1980, el valor de los intercambios comerciales totales de México era de 39,120 millones de dólares, y para 1997 ascendió a 220,175 millones de dólares.

Con esto, México logró colocarse como uno de los países con mayores intercambios comerciales en el mundo; la empresa maquiladora de exportación, sin duda, ha sido parte sustancial en este cambio (Mendiola, 1999).

Todo parece indicar que los efectos negativos del TLCAN sobre la economía mexicana se manifestarán en la "maquilización" (Kopinak, 1993), lo cual irá aparejado a un empeoramiento ambiental y de la calidad del empleo en México.

De esta manera, el TLCAN generaría un proceso de quiebra de empresas, cuyo resultado sería un mayor desempleo e incluso una reducción en el nivel salarial real, el cual cayó entre $23 \%$ y $40 \%$. Según estimaciones de la Universidad Obrera de México (UOM), en febrero de 1999 el costo diario de la canasta básica de cuarenta productos era de $\$ 101$, y el salario mínimo de $\$ 37.90$ (Hope, 2000).

De ahí que en los salarios de la industria manufacturera México presente un atraso frente a sus socios comerciales de la Unión Europea y de América Latina. Situación que, si se compara con Japón y Estados Unidos - considerados como mercados de los productos nacionales-, da como resultado que en nuestro país las remuneraciones en la industria manufacturera promediaron, en 1999, 3.83 dólares por hora, frente a 19.95 dólares del país nipón y 13.85 dólares del socio norteamericano (Chambuox-Leroux, 2001).

En el caso del incremento de las importaciones y exportaciones entre los Estados Unidos y México, destacan las características de un comercio intraindustrial que aumenta en forma significativa debido a un mayor grado de especialización de las empresas estadounidenses establecidas 
en México, de donde ha resultado la conformación de una organización industrial en ciertos sectores de la economía mexicana, robustecida desde la entrada en vigor del TLCAN (Kopinak, 1993).

De ahí que no resulte difícil aceptar afirmaciones como la siguiente: "[...] la globalización de las empresas está reestructurando el comercio mundial, más aún que lo sugerido por los datos de la tradicional balanza de pagos" (Kuri, 1994: 24). Y es que el comercio intrafirma entre unidades de corporaciones transnacionales representa ahora la mayor parte del comercio global, por lo que los flujos comerciales sólo serían una transferencia entre dos firmas de un mismo país.

Cabe aclarar que el comercio intrafirma se ha dado especialmente en un proceso atomizado de producción mundial. Esta fragmentación puede atribuirse, por lo menos, a dos causas: los esfuerzos por lograr competitividad internacional -mediante economías de escala o el uso de ventajas nacionales específicas - y la necesidad de eludir barreras no arancelarias. La estrategia de fragmentar procesos productivos consiste en reubicar en el extranjero las etapas ineficientes para que la mano de obra barata, entre otros componentes, pudiera abatir los costos de producción. Este tipo de inversión externa motivó que la maquila empezara a extenderse en forma considerable en los países en desarrollo (Mattar y Schatan, 1993).

Los procesos de apertura económica de México han transformado la magnitud y el tipo de comercio; predomina el de carácter intraindustrial o intrafirma, liderado por empresas transnacionales. Una parte significativa corresponde a las transacciones dadas al interior de estas empresas, como resultado de la internacionalización de los procesos productivos.

En relación con la cadena de producción de diversos bienes, las empresas transnacionales distribuyen entre 
sus casas matrices y filiales, en el resto del mundo, diversos eslabones productivos, produciendo un mismo bien al interior de la firma para un mercado global en diversas naciones (Capdvielle, Molina y Rosado, 1999).

A pesar de los efectos negativos generados por la maquila, no podemos negar que en los últimos seis años (cuadro 5) va en aumento su participación en algunos de los rubros macro.

Cuadro 5

Principales indicadores de la industria maquiladora

\begin{tabular}{|c|c|c|c|c|c|c|}
\hline & 1995 & 1996 & 1997 & 1998 & 1999 & 2000 \\
\hline \multicolumn{7}{|l|}{ Empleo 1/ } \\
\hline Miles de trabajadores & 685.3 & 799.3 & 936.8 & $1,038.8$ & $1,196.7$ & $1,277.7 *$ \\
\hline Variación anual \% & 13.4 & 17.3 & 17.2 & 10.9 & 15.2 & $14.1^{* *}$ \\
\hline $\begin{array}{l}\text { Participación en el empleo } \\
\text { manufacturero \% 2/ }\end{array}$ & 23.7 & 24.9 & 26.6 & 28.2 & 31.0 & $32.0 * *$ \\
\hline $\begin{array}{l}\text { Generación neta de divisas } \\
\text { (millones de dólares) }\end{array}$ & 4,924 & 6,416 & 8834 & 10,526 & 13,444 & 7,971 \\
\hline \multicolumn{7}{|l|}{ Valor agregado bruto 3/ } \\
\hline Millones de pesos corrientes & 33,183 & 49,738 & 71,466 & 96,704 & 128,265 & $62,048^{* *}$ \\
\hline Variación real anual \% & 11.6 & 19.9 & 13.8 & 10.9 & 12.0 & $15.7 * *$ \\
\hline $\begin{array}{l}\text { Participación en el PIB } \\
\text { manufacturero \% }\end{array}$ & 9.5 & 10.1 & 11.6 & 12.9 & 14.4 & $14.7^{* * * *}$ \\
\hline $\begin{array}{l}\text { Participación en el PIB total } \\
\%\end{array}$ & 1.8 & 2.0 & 2.2 & 2.5 & 2.8 & $2.7 * * *$ \\
\hline $\begin{array}{l}\text { Remuneración medias reales } \\
\text { Variación anual \% }\end{array}$ & -6.0 & -5.5 & 1.8 & 3.0 & 2.2 & $5.6^{\text {*** }}$ \\
\hline
\end{tabular}

1/ A diciembre de cada año.

2/ Se refiere a empleos.

3/ Acumulado anual.

4/ Promedio anual.

* Cifras de junio.

** Cifras de mayo.

*** Cifras a marzo.

Fuente: Elaboración a partir de INEGI, 2001.

Sociedad №. 31 
Respecto al número de maquilas por sector de actividad, en 1996 se reportó la siguiente composición sectorial (gráfica 1).
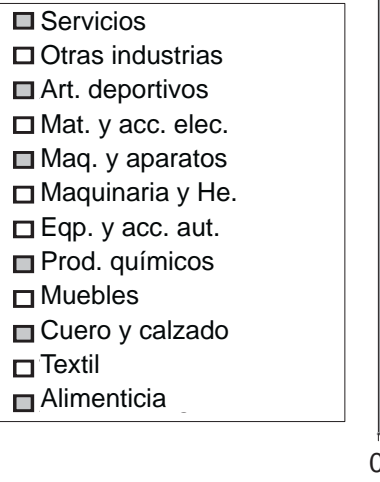

Maquiladoras en México, por ramas de actividad

Como se aprecia, los sectores de actividad que concentran al mayor número de establecimientos maquiladores son: textil, con $26.1 \%$; materiales y accesorio eléctricos y electrónicos, $19 \%$; muebles, partes y productos de madera, $12 \%$; equipo y accesorios automotrices, $7.2 \%$.

El crecimiento de la industria maquiladora en el país ha mantenido dos vertientes: el ensamble tradicional intensivo en mano de obra, y la tendencia a una nueva industria maquiladora más intensiva en capital y procesos completos de manufactura; tendencia que apunta a plantas más complejas, intensivas en capital y altamente integradas a los corporativos transnacionales. Estos cambios se deben a las pautas de competencia internacional en industrias de 
punta, particularmente en la electrónica y automotriz.

\section{Conclusiones}

Se ha explicado cómo la nueva política industrial define pautas para ofrecer un espacio territorial a la inversión extranjera, pero no a partir de la construcción de las ventajas comparativas clásicas (recursos naturales y mano de obra abundante y barata), sino que se combina con la creación ex profeso de ventajas competitivas basadas no sólo en una reducción constante del salario real, sino implementando políticas que subsidien (estímulos e incentivos de promoción industrial) a las filiales de los corporativos transnacionales.

Al surgir nuevos escenarios en una economía globalizada, cambia la percepción de quien queda fuera de las grandes redes del comercio mundial: podría verse retrasado en su desarrollo. De ahí que surja la necesidad de aplicar un giro radical en la política comercial, el cual consiste en desmantelar las restricciones cuantitativas a las importaciones, abatir los aranceles e impulsar a las exportaciones, rasgos comunes a una multiplicidad de países en desarrollo.

La estrategia de desarrollo adoptada en los años ochenta por el gobierno mexicano - al igual que en la mayoría de los países latinoamericanos- ha experimentado un vuelco notable en los últimos años. Los ensayos liberalizadores en América Latina se han realizado en forma brusca y con un "Estado pasivo", en donde predomina el desmantelamiento de la protección y de otros controles gubernamentales.

De ahí que el programa de liberalización comercial iniciado en 1985 haya tendido a eliminar los controles cuantitativos para un gran número de posiciones arancelarias.

A fines de 1987, junto con la introducción del llamado Pacto de Solidaridad Económica, se profundizó la reforma comercial: se eliminó una buena parte de los permisos 
previos que afectaban a las importaciones de bienes de consumo y se simplificó el arancel, reduciéndolo a sólo cinco tasas, en un rango de $0 \%$ a $20 \%$. Ello representó un vuelco importante en la orientación del desarrollo: ya no hacia el mercado interno sino al externo. Esto se ha traducido en lo siguiente: el arancel nominal medio ha caído de 100\% a $13 \%$, el arancel es uniforme y parejo para todas las importaciones y se han eliminado gran parte de las barreras no arancelarias.

En la nueva concepción de las economías en desarrollo, la aplicación de dicha apertura comercial externa tiene un carácter urgente, por lo que la política comercial se convierte en la estrategia idónea que permite una sincronización más dinámica entre las economías nacionales y las grandes corrientes del comercio internacional. Al aplicarse reformas comerciales liberalizadoras, éstas fortalecen la presencia del comercio internacional de las regiones periféricas o semiperiféricas en las redes del comercio y de las finanzas internacionales.

La cuestión, como lo apunta Pipitone (1997), es que la integración a los mercados internacionales puede ocurrir en una lógica de piel de leopardo, en donde aquello que se gana en integración en los mercados exteriores se pierde en términos de potencial de integración y dinamismo de los mercados internos. Fenómeno que, al parecer, sucede en las regiones periféricas, pues en lugar de expandir y consolidar su frontera productiva nacional, éstas se debilitan para darle acomodo prioritario al capital transnacional en sus espacios económicos.

Por esta razón encontramos al nuevo régimen de acumulación mexicano inscrito dentro de una filosofía de internacionalización del capital, con el objetivo de que la nueva dinámica productiva consolide un modelo promotor de exportaciones que sea impulsor de la ofensiva exportadora de México, orientado principalmente al mercado de los 
Estados Unidos, estimulado por una estrategia específica de fomento y privilegiado a través de políticas arancelarias para la importación, así como otros incentivos tales como los programas Pitex y Altex, esquemas fiscales, aduaneros y administrativos que simplifican los trámites para facilitar la instalación de dichos capitales en el país. Ambos, Pitex y Altex, son programas que otorgan facilidades administrativas y de apoyos concedidos por el gobierno para el establecimiento y operación de empresas maquiladoras, mediante los cuales se permite la importación temporal, libre del pago de aranceles, de la maquinaria, equipo y materias primas para llevar a cabo sus procesos productivos (en 1985 se implementaron los decretos que daban vida a los programas de importaciones temporales y altamente exportadoras: Pitex y Altex).

Este desarrollo no se detiene: en los años ochenta, el número de plantas de subcontratación internacional en el interior del país se incrementa considerablemente, a tal grado que la tasa de crecimiento de las empresas maquiladoras en Yucatán, Aguascalientes, Puebla y el propio estado de Jalisco supera a los estados de la franja fronteriza (CNIME, 2000). Cabe insistir en que la estructura y el desempeño de las exportaciones de México, e incluso de algunos países centroamericanos, han variado sobremanera en las dos últimas décadas (CEPAL, 1999).

Ahora bien, aquellos países que como México solían depender demasiado de las exportaciones de productos primarios comienzan a perder participación en el mercado de dichos productos.

Actualmente, podemos apreciar cómo se exportan principalmente productos manufacturados. Si bien este modelo de industrialización y el cambio de giro productivo no han dado espectaculares resultados en beneficio de las medianas y pequeñas empresas locales, sí han sido significativos 
para el grupo de empresas transnacionales orientadas al mercado externo.

La evaluación del proceso maquilador en términos económicos no debe llevarse a los extremos excluyentes de un saldo positivo o negativo. La maquila ha respondido a las expectativas de ser una fuente generadora de empleos, y en su conjunto representa un balance positivo para aminorar de alguna forma la tasa de desempleo general en el país. Aunque, también, la maquila arroja un saldo negativo: al depender de una política industrial discriminatoria a favor de la inversión extranjera, se ha desarrollado un segmento productivo ensamblador perteneciente a un corporativo transnacional, y ello impide queste tipo de maquila - por

Bibliografía la forma en que está concebida-genere efectos a favor de empresas nacionales y locales.

Banco de México, Datos de comercio exterior, México, Banco de México- INEGI, 1999.

Buitellar, R. y R. Padilla, "Industria maquiladora y cambio técnico", en Revista de la CEPAL, núm. 67, 1999.

Capdevielle, C., V. Molina y B. Rosado, "Especialización productiva y comercio internacional en la industria manufacturera", en Flores, J. y F. Novelo (coords.), Globalización, Estado y actores sociales, Universidad Autónoma Metropólitana-X, 1999.

CEPAL (Comisión Económica para América Latina), Informe anual de inversión extranjera en América Latina y el Caribe, Santiago de Chile, CEPAL, 1998.

—- Informe anual de inversión extranjera en América Latina y el Caribe, Santiago de Chile, CEPAL, 1999.

CNIME (Consejo Nacional de la Industria maquiladora de Exportación), Reporte de investigación, México, CNIME, 2000.

Chamboux-Lerouz, J., "El desequilibrio y la deuda externa 
como limitantes del desarrollo", en Renglones, núm. 47, ITESO, 200I.

"El comercio exterior de México", en El Financiero, 2000, noviembre 10, p. 9A.

Fajnzylber, F., "Oligopolio, empresas transnacionales y estilos de desarrollo", en Fajnzlber, F. (comp), Industrialización e internacionalización en América Latina, Trimestre económico del FCE, selección 34, 1980.

Fitzgerald, V., "La CEPAL y la teoría de industrialización”, en Revista de la CEPAL, número extraordinario, 1998.

Hope, M., "Salarios: la deuda pendiente de la macroeconomía”, en Expansión, núm. 897, 2000.

INEGI, Reporte anual del comercio exterior de México, México, INEGI, 2000.

Kopinak, K., "The maquiladorization of the mexican economy", en Grispun, Ricardo y Maxwell A. Cameron (edits.), The political economy of North American Free Trade, Londres, McGill-Queen's University Press-Montreal \& Jingston, 1993.

Krugman, P. y Obstfeld, M., Economía internacional y teoría política, Madrid,_McGraw-Hill, 1999.

Kuri, G., "El comercio mundial y la inversión extranjera directa", en Economía Informa, UNAM, Facultad de Economía, núm. 228, abril, 1994.

Mattar, J y C. Schatan, "El comercio intraindustrial e intrafirma México-Estados Unidos: autopartes, electrónicos y petroquímicos”, en Comercio Exterior, núm. I03, vol. XXIX, 1993.

Mendiola, G., "México: empresas maquiladoras de exportación en los noventa", en Revista de la CEPAL, núm. 49, vol. 4 (serie: Reformas económicas), diciembre de 1999.

Morales, J., "La reestructuración industrial", en Morales, J. (coord.), La reestructuración industrial en México. Cinco aspectos fundamentales, México, UNAM-Ed. Nuestro Tiempo, 1992.
Bibliografía 
Bibliografía | Mortimore, Michael et al., "Un análisis de su competitividad internacional, desarrollo productivo", en Revista de la CEPAL, núm. 62, vol. 15 (serie: Desarrollo productivo), abril de 2000.

Pipitone, U., Tres ensayos sobre desarrollo y frustración: Asia Oriental y América Latina, México, Miguel Ángel Porrua, 1997.

Polese, M., Ventaja competitiva, Cartago, Costa Rica, McGraw-Hill, 1998.

Porter, M., Ventaja competitiva, Madrid, McGraw-Hill, 1996.

Saldaña, J. y L. González, "La dinámica económica de la industria de ensamble", en El Financiero, 15 de junio de 2000 , p. 3.

Sandoval, R., "La maquila como sector exportador", en El Financiero, mayo I de 2000, p. 5A.

Seijal (Sistema Estatal de Información Jalisco), Serie Histórica de Estadísticas del Estado, Estadísticas de Jalisco, Zona Metropolitana de Guadalajara, Seijal y Secretaría de Promoción Económica, 1999. 